\title{
O CONHECIMENTO DO PROFESSOR EM TEMPOS DE MUDANÇA CURRICULAR. O CASO DA TELESCOLA PORTUGUESA (1965-1967)'
}

\author{
El conocimiento docente en tiempos de cambio \\ curricular. El caso de la Telescola portuguesa \\ (1965-1967)
}

\section{Teacher knowledge in times of curricular change. The case of the Portuguese Telescola (1965-1967)}

\author{
Mária Cristina Almeida \\ Correo-e: ajs.mcr.almeida@gmail.com \\ José Manuel Matos \\ Universidade Federal de Juiz de Fora. Universidade Nova de Lisboa \\ Correo-e: jmm@fct.unl.pt
}

Unidade de Investigação Educação e Desenvolvimento. Universidade Nova de Lisboa

Recepción: I8 de julio de 2020. Envío a informantes: 20 de julio de 2020

Aceptación definitiva: 28 de octubre de 2020

Resumo: Este artigo procura conhecer os modos como a comunicação de ideias matemáticas foi levada a cabo na implementação da Telescola em Portugal durante os anos de i965/66 e i966/67 e que, para além do uso educativo da televisão, incorpora também a inovação curricular da Matemática Moderna. Este artigo investiga os saberes matemáticos expressos em documentação associada aos dois anos letivos iniciais da Telescola em Portugal (1965/66 e 1966/67). Procuraremos identificar não só o conhecimento comum do conteúdo matemático, mas especialmente o seu conhecimento especializado. Procuraremos igualmente determinar como esses conhecimentos evoluíram em consequência da introdução da matemática moderna.

Este trabalho foi parcialmente financiado por fundos portugueses através da FCT - Fundação para a Ciência e a Tecnologia, I. P., no contexto dos projetos PTDC/CED-EDG/32422/20I7 e UID/ CED/O286I/20I9. 
O estudo baseia-se numa análise de conteúdo dos guiões publicados no Boletim IMAVE complementados com entrevistas ao professor das aulas televisionadas.

Palavras chave: conhecimento profissional do professor; História do Ensino da Matemática; matemática Moderna; televisão educativa; História Cultural.

Resumen: Este artículo busca comprender las formas en que se llevó a cabo la comunicación de ideas matemáticas en la implementación de Telescola en Portugal durante los años 1965/66 y 1966/67 que, además del uso educativo de la televisión, incorpora también la innovación curricular de la Matemática Moderna. Este artículo investiga los conocimientos matemáticos expresados en la documentación asociada a los dos primeros cursos académicos de Telescola en Portugal (1965/66 y 1966/67). Intentaremos identificar no solo el conocimiento común del contenido matemático, sino especialmente su conocimiento especializado. También buscaremos determinar cómo evolucionó este conocimiento como resultado de la introducción de las matemáticas modernas. El estudio se basa en un análisis de contenido de los guiones publicados en el Boletín IMAVE, complementado con entrevistas al profesor responsable de las clases televisadas.

Palabras Clave: conocimiento profesional del docente; Historia de la Enseñanza de las Matemáticas; Matemáticas Modernas; televisión educativa; Historia Cultural.

AвSTRACT: This article seeks to understand the ways in which the communication of mathematical ideas was carried out in the implementation of Telescola in Portugal during the years 1965/66 and 1966/67 which, in addition to the educational use of television, also incorporates the curricular innovation of Modern Mathematics. This article investigates the mathematical knowledge expressed in documentation associated with the initial two academic years of Telescola in Portugal (1965/66 and 1966/67). We will try to identify not only the common knowledge of the mathematical content, but especially its specialized knowledge. We will also seek to determine how this knowledge evolved as a result of the introduction of modern mathematics. The study is based on a content analysis of the scripts published in the IMAVE Bulletin, complemented with interviews with the teacher responsible for the televised classes.

KEY wORDs: teacher's professional knowledge; History of Mathematics Teaching; Modern Mathematics; educational television; Cultural History.

\section{Consideraciones iniciais}

$\mathrm{P}$

RETENDE-SE CONHECER os modos como a comunicação de ideias matemáticas foi levada a cabo na implementação da Telescola em Portugal durante os anos de 1965/66 e 1966/67 e que, para além do uso educativo da televisão, incorpora também a inovação curricular da Matemática Moderna. Este artigo 
investiga os saberes matemáticos a ensinar expressos em documentação associada aos dois anos letivos iniciais da Telescola em Portugal (1965/66 e 1966/67). Procuraremos identificar não só o conhecimento comum do conteúdo matemático, mas especialmente o seu conhecimento especializado. Procuraremos igualmente determinar como esses conhecimentos evoluíram em consequência da introdução da matemática moderna. $\mathrm{O}$ estudo baseia-se numa análise de conteúdo dos guiões publicados no Boletim IMAVE complementados com entrevistas ao responsável das aulas televisionadas.

Tem sido essencialmente as pesquisas históricas, em particular as estimuladas pelas propostas de Chervel e Julia e ancoradas no paradigma da história cultural que têm problematizado o saber escolar². A partir dos anos I990, ao se propor que as disciplinas escolares são uma criação original da escola (Chervel, I988) e que os investigadores deveriam valorizar a sua autonomia (Julia, I995), o estatuto do saber veiculado por estas disciplinas ganhou destaque, quer em relação ao saber académico, quer em relação às grandes determinantes sociológicas e culturais que envolvem o ambiente escolar. No primeiro caso - o pressuposto da originalidade do saber escolar -, as novas propostas configuram um corte com a teoria da transposição didática de Chevallard (I99I). No segundo, o movimento acompanhou as tendências de uma «nova» história cultural de raiz antropológica, procurando significados e descrições fenomenológicas densas, afastando-se de descrições globais centradas em determinantes económicos ou sociais (Burke, I997; Hunt, 1989).

Estas novas perspectivas entroncam bem com os estudos educativos iniciados por Shulman (I986) que vieram dar uma nova visão sobre o conhecimento do professor. Nos seus primeiros trabalhos sobre o tema, este autor propõe alguns componentes para o conhecimento do professor, entre eles o conbecimento do conteúdo (content knowledge) e o conbecimento pedagógico do conteúdo (pedagogical content knowledge). O destaque dado a este último, relevando a sua originalidade e a sua indissociabilidade da prática docente, para além de dar uma visão inovadora sobre o saber do professor, tornando-o indispensável numa apreciação da qualidade do ensino, trouxe-o para o centro das políticas educativas, mostrando como é essencial para a compreensão da escola e para o desenho de alterações curriculares e formativas.

Os trabalhos de Shulman permitiram compreender como o conhecimento característico da profissão docente, embora contendo uma componente teórica, possui igualmente uma forte ligação à prática. Várias profissões partilham esta dualidade. Para alguns estudiosos da sociologia das profissões: «o saber profissional tem uma forma dual de conhecer que permite a coexistência de saberes pouco conscientes do fazer e do pensar com princípios e conhecimentos abstratos e formais em contextos de ação e em situações práticas, sem nunca os fundir ou separar totalmente» (Caria, 20I7: 498), embora não seja possível estabelecer uma fronteira nítida entre estes dois tipos de conhecimento.

Neste texto usaremos indistintamente os termos saber e conhecimento. 
Estudar historicamente o conhecimento profissional docente é relevante. No caso da educação matemática, estes estudos têm incidido sobre docentes atuais e os estudos históricos, ao abordar o passado e debruçando-se portanto sobre realidades diferentes das contemporâneas, vão permitir novas visões sobre a natureza, e principalmente a génese, do conhecimento profissional e sobre a sua modificação em contextos de alterações curriculares (Matos, 2020). Mas esse estudo é também relevante para traçar uma história cultural da educação, pois conhecer o percurso desse saber é fundamental para compreender as escolas enquanto entidades geradoras de cultura (Julia, 1995).

A investigação histórica sobre o conhecimento do professor tem realizado o seu trabalho baseando-se essencialmente em fontes escritas: livros didáticos e relatórios de professores e apenas ocasionalmente recorreu a entrevistas fazendo assim predominar a componente teórica da profissão. E no entanto, este conhecimento, como vimos, contempla simultaneamente um saber teórico e abstrato e outro associado à ação e à prática. Barbier (1996: 9) distingue entre os saberes possuídos (savoirs détenus) compostos de capacidades, conhecimentos, competências, aptidões, atitudes e profissionalidades que se relacionam com a identidade de uma profissão e que são apenas inferidos através de uma metodologia de observação de comportamentos e os saberes objetivados (savoirs objectivés)

que pertence[m] à mesma zona semântica que, por exemplo, a cultura, as regras e os valores. Esta primeira zona remete provavelmente a realidades que têm o estatuto de representações ou de sistemas de representações dando lugar a enunciados proposicionais e tornando-se objeto de uma valorização social sancionada por uma atividade de transmissão-comunicação. Elas têm por isso uma existência distinta daqueles que as enunciam ou daqueles que delas se apropriam. São conserváveis, acumuláveis, apropriáveis (Barbier, 1996, p. 9, tradução nossa).

A pesquisa histórica tem-se debruçado essencialmente sobre este segundo tipo de saberes, admitindo que parte do conhecimento do professor se encontra representado em livros escolares ou em outro material impresso. Será essa a nossa opção neste texto. Estudamos pois saberes objetivados que postulamos como uma condensação de saberes que no passado tiveram uma forte ligação com a prática docente.

Importa ainda clarificar o conceito de conhecimento profissional docente que pretendemos estudar. Como vimos, Shulman propôs que esse conhecimento seria composto por diversos tipos de saberes interligando dimensões relacionadas com a reflexão e a ação. Uma revisão sobre desenvolvimentos do seu trabalho pode ser encontrada em Ball, Thames e Phelps (2008). Também os trabalhos de Hofstetter e Schneuwly se têm preocupado com os saberes relacionados com o ensino e a formação (ver, por exemplo, 2009). Focando-se, em particular, nos saberes formalizados (Hofstetter e Schneuwly, 2009: 17), e afastando-se pois das abordagens que incorporam a dimensão prática desses saberes, distinguem entre saberes a ensinar (savoirs à enseigner), isto é, aqueles que são o objeto do ensino 
e que constituem o centro da atividade do professor e os saberes para ensinar (savoirs pour enseigner), constituídos por conhecimentos sobre o que vai ser objeto de formação e que são como que ferramentas que os docentes utilizam para ensinar os primeiros.

Estes dois modelos têm um âmbito geral e aplicam-se ao conhecimento dos docentes de qualquer disciplina. No entanto, quando o foco é uma história de disciplinas escolares concretas, em particular de matemática, e não uma história da educação em geral, sentimos necessidade de modelos que tomem em conta as características dos saberes disciplinares específicos. Saberes de disciplinas artísticas, de educação física, de línguas, de matemática, etc. não podem ser tratados da mesma forma. Nesse sentidos quer os saberes a ensinar quer os saberes para ensinar necessitam de uma abordagem mais fina.

Assim, outros investigadores, incluindo o próprio Shulman, têm elaborado modelos que permitem um maior detalhe na caraterização do conhecimento profissional docente. De entre estes autores, merece-nos destaque o trabalho de Ball, Thames e Phelps (2008) que, desenvolvendo as propostas de Shulman e baseandose na observação das atividades de aula de matemática e na análise de tarefas do professor, distinguem diversos saberes (que denominam «domínios»), permitindo destrinçar melhor os conceitos de «matemática» e de «didática», tornando-os mais adaptados ao estudo dos saberes matemáticos escolares. Como neste artigo vamos analisar saberes objetivados, interessa-nos particularmente aqueles saberes que têm que ver com a dimensão mais teórica do conhecimento docente. Assim centrar-nos-emos em dois dos propostos por aqueles autores. $\mathrm{O}$ primeiro, o conbecimento comum do conteúdo (common content knowledge), refere-se ao conhecimento e competências matemáticas que também são usados noutros contextos para além da escola. O segundo domínio refere-se ao conbecimento especializado do conteúdo (specialized content knowledge), composto de tarefas matemáticas que normalmente são executadas pelos professores para apresentar ideias matemáticas, responder a perguntas de «porquề dos alunos, encontrar exemplos para um aspeto matemático específico, reconhecer o que envolve utilizar uma representação específica, relacionar representações com as ideias subjacentes e com outro tipo de representações, relacionar um tópico que se vai ensinar com outros tópicos que já foram trabalhados ou que ainda se vão trabalhar, explicar os objetivos da disciplina aos pais, avaliar e adaptar os conteúdos matemáticos dos manuais, alterar as tarefas a propor, tornando-as mais fáceis ou mais difíceis, avaliar a plausibilidade do que é pedido pelos alunos, dar e avaliar explicações matemáticas, escolher e desenvolver definições, usar notação e linguagem matemática e criticar o seu uso, fazer questões matematicamente produtivas, escolher representações com um propósito específico e averiguar equivalências. Embora apenas exista em contextos de ensino, este conhecimento envolve um saber matemático que vai para além daquele que se tem de ensinar aos alunos. Ball, Thames e Phelps dão alguns exemplos deste tipo de conhecimento mostrando como se trata de um saber que, embora do domínio da matemática, apenas existe e faz sentido em contexto escolar. 
De um ponto de vista epistemológico, é importante realçar que assumimos a natureza essencialmente escolar destes saberes. Autores centrados na formação profissional em educação tendem a adotar uma outra visão, assumindo-os como «emanando dos campos disciplinares de referência» (por exemplo, Borer, 2009: 42, tradução nossa), por vezes, recorrendo ao conceito de transposição didática. Trabalhos em história da educação matemática (Matos, 2020; Valente, 2007) têm defendido a necessidade de recusar a utilização deste conceito, porque ele menospreza a importância dos saberes disciplinares e desvaloriza a autonomia das disciplinas escolares realçada por Chervel e Julia, que defenderam que estes saberes têm a sua origem na escola, sendo portanto saberes escolares e não meras adaptações de saberes académicos.

\section{Propósito deste artigo}

Este artigo prolonga trabalhos anteriores (Almeida, 20I8; Almeida e Matos, 20II; Barros, 2013) e investiga os saberes matemáticos a ensinar expressos em documentação associada aos dois anos letivos iniciais da Telescola em Portugal (1965/66 e 1966/67). Procuraremos agora identificar não só o conhecimento comum do conteúdo matemático, mas especialmente o seu conhecimento especializado. Procuraremos igualmente determinar como esses conhecimentos evoluíram em consequência da introdução da matemática moderna.

Será realizada uma análise de conteúdo dos guiões das lições publicados na revista Boletim IMAVE ${ }^{3}$, correspondentes aos anos em estudo. Nesse Boletim eram impressas antecipadamente as indicações didáticas, os textos das lições e as indicações aos monitores. Esses textos serão o corpus essencial deste trabalho, complementado com a análise de documentos oficiais e entrevistas realizadas ao longo de 2008 e 2009 ao responsável das aulas televisionadas durante aquele período, António Augusto Lopes (1917-20I5) (AAL), professor formador de professores liceais (metodólogo) no Liceu Normal de D. Manuel II, no Porto e que fazia parte da Comissão de Revisão do Programa do $3 .{ }^{\circ}$ Ciclo Liceal participando ativamente na experiência de introdução da Matemática Moderna nos liceus.

Nos dois anos em estudo, a quase totalidade dos textos das lições publicados no Boletim IMAVE tem uma estrutura semelhante: I) um Sumário que resume o conteúdo da lição, 2) um Esquema Descritivo ou Emissão que acompanha o guião televisivo executado pelo professor, 3) uma identificação do Material necessário durante a recepção ou após esta, e 4) indicações para uma Exploração conduzida pelo monitor, contendo diversas sugestões metodológicas e normalmente composta por exercícios de aplicação. As lições consagradas aos «Exercícios de apuramento» (6 ao longo do ano), as respectivas lições de «correção» são a exceção, pois apenas contêm o Sumário. Algumas das segundas contêm ainda indicações breves ou alguns exercícios.

No fim do primeiro ano, a designação da revista alterou-se para IMAVE: Boletim do Instituto de Meios Áudio-Visuais de Ensino. Neste texto usaremos o termo Boletim IMAVE. 


\section{O início da Telescola: contexto e motivações}

No início dos anos sessenta do século passado, a Educação era encarada social e politicamente em Portugal como um factor impulsionador do desenvolvimento económico (Teodoro, I999). A evolução da estrutura social da sociedade portuguesa e as alterações no mercado de trabalho obrigavam a uma melhor qualificação da população activa e levaram a uma crescente procura de educação no nível seguinte aos quatro anos do ensino primário. Este movimento acentuou carências já existentes, nomeadamente a baixa escolarização da população, a insuficiência de professores habilitados e a falta de estabelecimentos de ensino. Estando convicto de que os meios audiovisuais teriam um papel cada vez mais importante a desempenhar, o Ministro da Educação Nacional, Inocêncio Galvão Telles (I9I7-20I0), procede a partir da segunda metade dos anos I960 a uma rápida inovação no plano pedagógico: a utilização da televisão para fins escolares e educativos ${ }^{4}$. Assim, I2 de dezembro de 1963, numa exposição feita através dos canais de televisão e rádio estatais apresentou ao País as linhas gerais de um ambicioso programa destinado a melhorar a preparação escolar e cultural dos portugueses através da televisão anunciando o estabelecimento da TV Escolar e Educativa. A emissão dos programas da TV Escolar e Educativa começou efectivamente em 6 de janeiro de 1964. No ano seguinte será criado o Instituto de Meios Audiovisuais de Ensino (IMAVE) para promover a utilização, expansão e aperfeiçoamento das várias técnicas audiovisuais como meios adjuvantes e de difusão do ensino e de elevação do nível cultural da população.

Em 1965 é criada a Telescola associada ao IMAVE, uma organização central de carácter marcadamente pedagógico para conceber cursos, ministrá-los à distância e estruturar apoios educativos presenciais, assegurando o aproveitamento pelos alunos distantes. A sua sede seria em Vila Nova de Gaia, utilizando o estúdio de televisão aí existente e os programas seriam difundidos pelo único canal televisivo da época. Ainda nesse ano cria-se o Curso Unificado da Telescola (CUT), destinado a alunos com o diploma do ensino primário, composto pelas disciplinas (e respectivos programas) que constituíam o Ciclo Preparatório do Ensino Técnico Profissional, acrescidas pelo Francês e que iniciou as suas emissões em 25 de outubro de 1965. A Matemática dispunha de três horas semanais.

\section{O modelo pedagógico da Telescola}

Uma abordagem do ensino através da tecnologia televisiva vai exigir fortes mudanças no modelo pedagógico disseminado no resto do sistema escolar. Em Portugal, optou-se pela difusão de aulas leccionadas por um corpo escolhido de «professores» através de «postos de recepção», seguida de uma exploração pelos

4 Nestas duas secções apresentamos apenas os momentos essenciais da criação da Telescola. Muitos elementos foram retirados do relatório da OCDE (OCDE, 1977). O leitor interessado numa descrição mais detalhada poderá consultar Almeida (2018) ou Barros (2013). 
alunos de actividades apoiadas por um «monitor». Garantia-se assim que o mesmo professor, reputadamente um especialista na matéria, podia ser seguido simultaneamente por um elevado número de alunos nos mais diversos lugares, deixando a gestão quotidiana da aula, bem como a aplicação e a consolidação dos conhecimentos, a outros profissionais menos habilitados ou menos conceituados. O ciclo básico de aprendizagem era constituído por uma lição televisiva de 20 minutos (que se supunha corresponder à capacidade máxima de concentração dos alunos) seguida de uma exploração de 30 minutos, na aula, orientada por um monitor. O professor era o centro do programa televisivo. Existiam limitações devidas à ausência de comunicação directa entre o professor e o aluno e, para as colmatar, por um lado, o professor procurava estabelecer uma atmosfera análoga à da aula, dirigindo-se frequentemente à turma através da televisão e, por outro, o monitor podia formular perguntas directas a qualquer aluno ou à turma inteira. Nos primeiros anos as emissões eram usualmente em direto, para dar mais realismo ao processo de ensino e para introduzir alterações de última hora.

$\mathrm{O}$ contributo dos monitores era pois muito importante. Terminada a lição televisiva, tinha início o período de exploração a cargo dos monitores. $\mathrm{O}$ seu contributo era pois muito importante. A sua acção consistia, de modo geral, no reforço da lição televisiva na qual se deveriam integrar completamente. Se o tempo de que dispunham não era suficiente, uma parte do período mais longo de exploração, no final ou no início do dia, podia ser utilizado para terminar os exercícios ou ser dedicado a actividades criativas. $\mathrm{O}$ trabalho de casa era uma excepção. Excluía-se o trabalho de casa de carácter livresco, restringindo-o a uma extensão prática ou criativa do trabalho de aula, como por exemplo, procurar determinada notícia no jornal, plantar uma semente e observar o seu crescimento, medir o leite de uma vaca ou de uma cabra, etc. associando-o assim ao quotidiano dos alunos a quem preferencialmente se destinava o curso.

Os postos de recepção situavam-se normalmente em salas utilizadas durante a manhã para o ensino primário. Mais tarde, em algumas localidades, construíramse pavilhões próprios para acolher os alunos deste ensino. Cada posto tinha um administrador local e, cada sala estava sob a responsabilidade de um monitor a quem competia assegurar a disciplina, preparar a recepção, orientar os trabalhos de aplicação de que as lições eram normalmente seguidas, esclarecer dúvidas dos alunos e certificar-se do seu aproveitamento.

No ano de 1965/66 havia cerca de Ioo postos de recepção. Nos primeiros anos da Telescola, os adultos representavam cerca de io\% do auditório das emissões do CUT. Porém, com o passar do tempo esta proporção diminuiu em consequência do aumento do número de crianças e da prioridade que lhes foi atribuída face aos adultos. O número de postos foi aumentando e em I967/68 estava próximo de 600 .

Podiam ser monitores do CUT os professores habilitados de qualquer grau de ensino oficial, ou os que possuíssem o $3 .^{\circ}$ ciclo liceal, um curso médio, ou equivalente. Na prática, até $1974 / 75$, os monitores eram, na sua maioria, professores do ensino primário trabalhando em horas extraordinárias.

Com o objectivo de coordenar as acções pedagógicas entre professores e monitores, a Telescola procurava proporcionar a estes últimos uma preparação pedagógica e didática levada a cabo pelos professores responsáveis pelas disciplinas. Assim, inseridos na fase de preparação das actividades escolares, entre is e 25 de 
Outubro de 1965 e de i a is de Outubro nos anos subsequentes, realizaram-se programas de televisão diários de Orientação de Monitores, os quais visavam transmitir directrizes práticas de pedagogia e didáctica geral e de didáctica das diversas disciplinas.

Procurava-se igualmente institucionalizar ligações periódicas entre a Telescola e os postos através do Boletim IMAVE destinado a servir de orientação pedagógica aos monitores, onde eram publicados os Resumos das lições a proferir no mês seguinte, bem como outros esclarecimentos julgados necessários. Os monitores deviam completar as instruções proporcionadas por estes programas com a leitura e ponderação dos Guias de Trabalbo, organizados pela Telescola, das indicações didácticas incluídas no boletim e de alguma bibliografia aconselhada. No resto do ano, continuavam a ser transmitidos programas de Orientação de Monitores.

A disciplina de Matemática do CUT no ano lectivo 1965/66 (e em anos seguintes) foi apresentada por António Augusto Lopes. Quando o CUT se iniciou, era o único professor da disciplina de Matemática, acumulando a criação e a apresentação das emissões perante as câmaras bem como a elaboração de toda a documentação de apoio e os testes de avaliação. São pois da sua autoria as lições apresentadas ao professores através do Boletim IMAVE.

\section{O currículo matemático da Telescola}

O currículo da Telescola constitui a primeira generalização oficial das ideias da Matemática Moderna a todo um sub-sistema de ensino em Portugal, embora já então decorressem diversas iniciativas (cursos, conferências, etc.) incidindo sobre as novas ideias e estivesse em curso uma experiência curricular no último ciclo dos liceus. No que respeita ao programa de Matemática da Telescola, «enveredase abertamente - não sem algumas apreensões - pelos caminhos da Matemática Moderna, sem prejuízo do ensino das matérias constantes dos programas oficiais» (Boletim IMAVE, 1965, p. 12).

Conforme se esclarece logo na «Indicações didáticas de ordem geral» referentes à Matemática: «Compete ao monitor assegurar o desenvolvimento pleno da atividade dos alunos, como for determinado pelo professor e sem coarctar o ritmo próprio de cada aluno» (Boletim IMAVE, 1965, p. 83, negrito no original). A necessidade de imaginação e empenho regular, da parte do aluno, para uma aprendizagem efetiva é também realçada na indicações ao monitor: « $\mathrm{O}$ ato de aprender é um ato criador; aquele que aprende não pode, nem deve - por isso manter uma atitude receptiva, meramente passiva. É direito seu tomar parte ativa no aprendizado; é obrigação sua exercer esforço constante e metódico» (Boletim $I M A V E$, 1965, p. 83). Estas diretrizes evidenciam que a Telescola pretende criar uma cultura que coloque o aluno como um agente da sua aprendizagem.

Nas diretrizes didáticas gerais menciona-se que uma aprendizagem natural se suporta em três passos: «I. Observar; 2. Experimentar; 3. Refletir e concluir» (Boletim IMAVE, I965, p. 83). Salienta-se, para além da necessidade de «tomar o concreto como ponto de partida para o ABSTRACTo e recorrer à experimentação 
(real, figurada ou imaginada) para sugerir uma definição ou uma demonstração» (Boletim IMAVE, 1965, p. 83). Pretendia-se assim que fossem utilizados métodos ativos herdeiros das propostas da Escola Nova que envolvessem os alunos na elaboração do conhecimento.

No ano seguinte as intenções permanecem. Assume-se que a matemática a ensinar tem que ser atualizada, e o seu ensino, ao invés de impor ao aluno os raciocínios já elaborados «despersonalizando cada um dos educandos e, consequentemente, tirando-lhe a capacidade de atingir os níveis superiores do pensamento» (Boletim IMAVE, 1966, p. 85), tem que deixar o aluno em condições de descobrir por si próprio. Defendendo-se que na atividade docente deve prevalecer, cada vez mais, a observação e experimentação, toma-se «a iniciativa de introduzir trabalhos práticos. [...] [mas] não se trata de trabalhos manuais, ainda que com eles possam relacionar-se. E experiência que vai tentar-se [...] O cuidado atento do monitor é, aqui, indispensável» (Boletim IMAVE, 1966, p. 85, negrito no original).

Estes métodos de ensino devem ser usados para ensinar um programa imerso nas ideias da matemática moderna. Assim, desde a primeira lição, os conjuntos e suas operações são encarados como uma linguagem básica para a matemática e vistos como uma das grandes alterações introduzidas na matemática escolar pela reforma da Matemática Moderna. As cinco primeiras lições da Telescola, que corresponderam às primeiras duas semanas de aulas, foram consagradas à sua exploração. A Lição n. ${ }^{\circ}$ I, após apresentação do professor, aborda os «conceitos de conjunto (sinónimo: colecção) e de elemento de um conjunto (sinónimo: indivíduo, ser, objecto)» (Lição n. ${ }^{\circ}$ I, Boletim IMAVE, I965, p. 86)5. Imediatamente a seguir se enfatiza a distinção entre conjunto, elementos do conjunto e respectivas designações.

Figura I. Conjuntos, seus elementos e respectivas designações

(Boletim IMAVE, 1965, p. 86).

\begin{abstract}
2 - Em seguida, o professor apresenta o primeiro exercicio - que todos devem fazer I Trata-se de preencher uma tabela : - numa coluna figuram designaçōes de conjuntos: noutra coluna figuram as designaçõ̃es dos elementos desses conjuntos. De notar: qualquer formigueiro é um conjunto, mas um conjunto de formigas não 6 , necessàriamente, um formigueiro: o mesmo para outros casos semelhantes.
\end{abstract}

No final da emissão, o professor sintetiza que «um objecto (qualquer que seja a sua natureza) não deve ser confundido com o símbolo que o representa» (p. 86). Na fase de Exploração, o monitor coloca diversos «exercícios orais» (p. 88) e de revisão centrados na distinção entre conjunto e os seus elementos e na relação original.

Neste trabalho, quer o negrito, quer o itálico nas citações correspondem sempre a ênfases do 
de pertença. Nas lições seguintes vão ser introduzidos outros conceitos básicos sobre conjuntos, bem como as suas representações (simbologia, diagramas de Venn, «setas» representando relações binárias).

Esta ênfase na linguagem de conjuntos vai provocar alterações na forma de comunicar conhecimentos matemáticos. Observemos, por exemplo, o modo como a adição, que já tinha sido objecto de estudo no ensino primário, é retomada, não associada à contagem de agregações de objectos concretos, mas como o número de elementos da reunião de conjuntos disjuntos (Figura II) quase sempre constituídos por entidades AвsTRACTas. O mesmo pode ser observado no modo escolhido para ensinar as restantes operações aritméticas.

FIgURA II. A adição e a reunião de conjuntos disjuntos (Boletim IMAVE, 1965, p. IIT) ${ }^{6}$.

1 - Retoma-se a situaçà anterior, atraves de novos exemplos sobre reuniâo de conjuntos disjuntos: o número de elementos do conjunto reuniấo de dois conjumtes disjumtos $\ell$, por definigalo, a soma dos nómeros de elementos desses conjuntos:

$$
*(A \cup B)=\| A+* B
$$

Desta maneira, os alunos sào colocados a rever experiências anteriores - colhidas na escola primária e na vida quotidiana

O esquema de base a explorar em todas as situa cões é evidentemente o que a seguir se indica

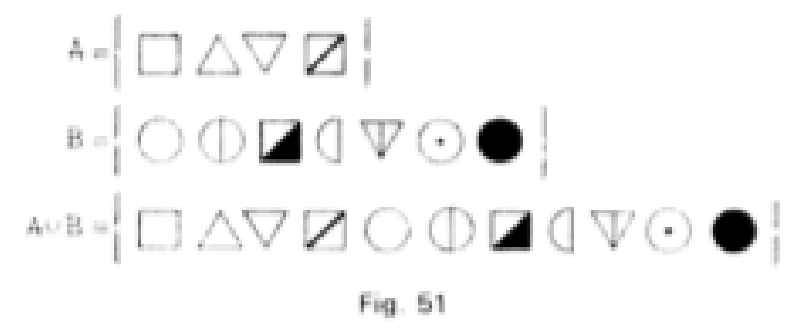

A mudança de matematizações com referência ao concreto para matematizações baseadas em entidades Авstractas e cuja legitimidade depende, não de regras derivadas do senso comum do mundo real, mas de regras construídas arbitrariamente, já tinha sido detectada para alunos da mesma faixa etária nos ma-

6 Apesar de o conceito de cardinal ter sido abordado na Lição n. ${ }^{\circ}$ 4, e de o seu símbolo ser utilizado nesta lição, o termo não é referido. 
teriais curriculares para o primeiro ano de funcionamento do Ciclo Preparatório do Ensino Secundário em 1968/69 (Matos, 2009).

A utilização da linguagem de conjuntos requer, no entanto, um enquadramento matemático mais complexo. Por exemplo, a importância de precisar qual o universo em que as operações são definidas requer que, logo após ter sido apresentada a «definição» de soma na Lição n. ${ }^{\circ}$ i3 (Boletim IMAVE, I965, p. II7), se discuta que a adição pode não ser nem uma lei de composição interna nem universal. No universo E,

$$
\mathrm{E}=\{0, \mathrm{I}, 2,3,4,5,6,7,8,9\} \text {, }
$$

a adição não está definida para todos os pares de elementos de $\mathrm{E}(3+4$ está definida, mas não 5 + 8) (Boletim IMAVE, I965, p. II7). A adição, cuja possibilidade não suscitava dúvidas no ensino primário (nem na «matemática clássica» dos primeiros ciclos das escolas técnicas e dos liceus), pois a sua legitimidade assentava num senso comum proveniente da experiência empírica, sensorial dos alunos, necessita agora que se precisem melhor todos os seus elementos constitutivos.

O facto de agora a constituição de conjuntos e as suas operações poderem obedecer a uma lógica independente do concreto, levanta igualmente problemas. Por exemplo, na mesma Lição n. ${ }^{\circ}$ iz é discutida a diferença entre a reunião de conjuntos e número de elementos (Figura III).

Figura III. Reunião de conjuntos e adição (Boletim IMAVE, I965, p. II7).

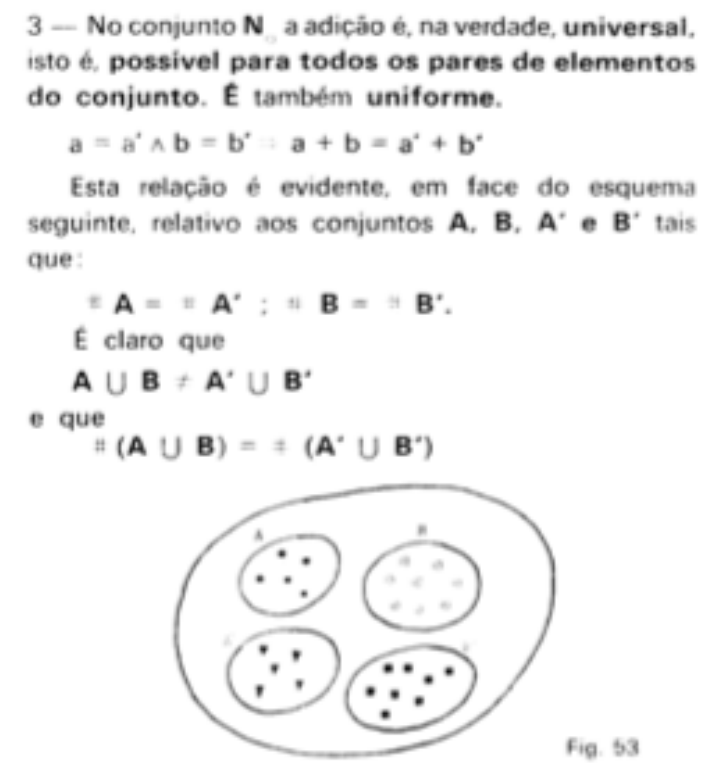

Enquanto que no ensino «clássico» podemos constituir classes de flores, ou de flores vermelhas, ou de rosas, por exemplo, são legitimadas pelo seu uso cultural, 
ao se pretender a maior generalidade, surgem colecções arbitrárias como as da Figura III que necessitam de cuidados especiais.

As restantes operações aritméticas vão ser igualmente objecto de reformulações linguísticas semelhantes, associando a subtracção à diferença entre conjuntos, a multiplicação ao cardinal do produto cartesiano e a divisão à partição de um conjunto e afastando-as portanto das experiências quotidianas dos alunos.

De modo semelhante, a abordagem através da nova linguagem vai chegar à geometria. No esquema descritivo da Lição $n .^{\circ} 76$, explicava-se que, em primeiro lugar, a atividade dos alunos seria orientada no sentido de estes compreenderem: «I. $\left.^{\circ}\right)$ no plano, os pontos geram linhas; $2^{\circ}$ ) as linhas podem ter pontos comuns; $\left.3 .^{\circ}\right)$ com determinadas linhas (conjuntos de pontos) delimitam-se regiões planas (novos conjuntos de pontos)» (Boletim IMAVE, I966, p. 49). Num segundo momento, passaria «a ser orientada no sentido de os alunos assimilarem o conceito de 'estrela de rectas no plano' a partir dos seus conhecimentos anteriores (de base experimental e intuitiva)» (Boletim IMAVE, 1966, p. 49) (Figura IV).

Figura IV. Ilustrando uma estrela de rectas de centro $P$ e uma Partição do plano (E) por uma recta (r) (Boletim IMAVE, 1966, p. 49).

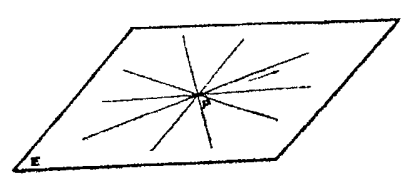

Estrela de rectas de centro $P$.

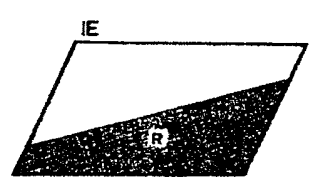

Partição do plano (E) por uma recta $(\mathrm{R})$

Em seguida, seriam introduzidos os conceitos de semirreta e segmento de recta. Tomando uma recta no plano, a possibilidade de considerar sobre ela, com referência a um ponto $P$, as relações: estar depois de, não estar antes de, estar antes de, não estar depois de (já conhecidas dos alunos), iriam suportar a referida introdução de acordo com esquemas gráficos apresentados (Figura V). 
FIgURA V. Ilustrando os conceitos de semirreta e segmento de recta

(Boletim IMAVE, I966, p. 49).

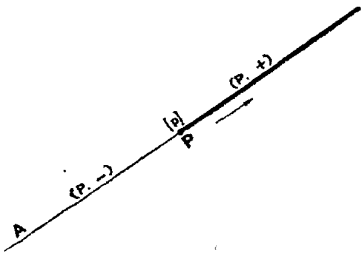

$(P,+) \cap(P,-)=\{p\}=P$

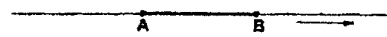

$\overline{A B}=(A,+) \cap(B,-)$

No prosseguimento da lição, estava previsto que o professor conduzisse os alunos na execução de um exercício, que consistia em dobrar e vincar uma folha de papel. «O vinco é a imagem de uma recta» (Boletim IMAVE, I966, p. 49).

Embora António Augusto Lopes tenha muita preocupação com o uso de materiais para ilustrar estes conceitos aritméticos e geométricos (Almeida, 20I8), a linguagem dos conjuntos e suas relações afasta-os do seu significado na vida corrente. Esta consequência da reforma tem sido abordada noutros graus de ensino (Matos, 2008, por exemplo) e, seguindo o modelo de Ball, Thames e Phelps (2008) o que nos programas anteriores era conhecimento comum do conteúdo transforma-se agora em conhecimento específico do conteúdo.

\section{Desenvolvendo o conhecimento específico do conteúdo}

É a primeira vez que as novas ideias estão a ser aplicadas a alunos portugueses desta idade e AAL não possui qualquer tipo de apoio para além de documentação estrangeira e portanto provinda de outro contexto. É natural pois que estas alterações dos conteúdos matemáticos provocados pela ênfase na linguagem de conjuntos e das suas operações levem AAL a experimentar a sua adequação a temas não usuais, desenvolvendo ideias matemática originais. Tomemos, por exemplo, a Lição n. ${ }^{\circ}$ 4I emitida a 23/2/66 (Boletim IMAVE, I966, p. 57) cujo Sumário se centrava em operações sobre figuras geométricas. Durante a emissão, AAL planeava discutir a junção de figuras geométricas utilizando a linguagem dos conjuntos. A Figura VI mostra a primeira página desta Lição que discutiu as operações de adição e subtracção no conjunto das figuras planas e as operações de multiplicação e divisão de uma figura plana por um número natural, bem como o conceito de fracção de uma figura plana. 
O COHECIMENTO DO PROFESSOR EM TEMPOS DE MUDANÇA CURRICULAR

O CASO DA TELESCOLA PORTUGUESA (I965-I967)

MÁRIA CRISTINA ALMEIDA Y JOSÉ MANUEL MATOS

Figura VI. O Sumário e o início da Emissão da Lição n. ${ }^{\circ} 4 I$ (Boletim IMAVE, I966, p. 57).

I - SUMARIO

1. A operação adição, definida no conjunto das figuras planas; diferença de duas figuras planas.

2. Multiplicą̧ão e divisão de uma figura plana por um número natural; fraç̧ão de uma figura plana.

II - EMISSÃO

A - Esquema descritivo:

a) Feita uma breve sintese oral da lição anterior, o professor esclarece os alunos sobre o significado da adicão de superficies, definida no conjunto das figuras planas. Simultanneamente, os alunos realizam eles próprios a operação, com modelos de que dispōem. Para o efeito, os alunos observaram uma primeira
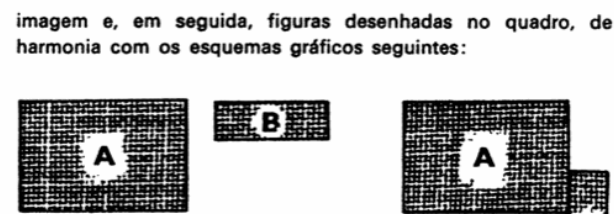

\section{焉}
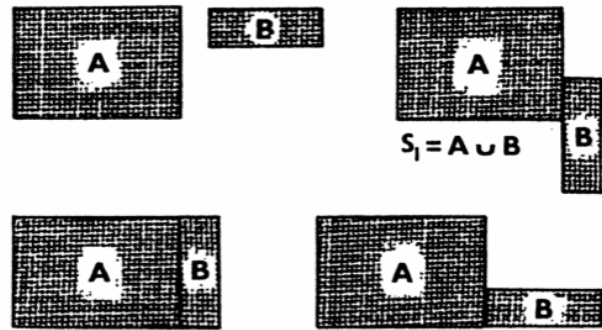

$S_{2}=A \cup B$
A

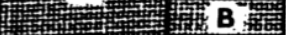

$S_{3}=A \cup B$

57

A operação de adição dos dois rectângulos, formulada na linguagem dos conjuntos, tem alguma complexidade. Por um lado, o resultado da operação depende do modo como ela for concretizada (a Figura VI mostra três resultados distintos), por outro, implicitamente assume-se que a «posição inicial» não é uma figura, mas duas, o que levanta problemas quanto a um possível «elemento neutro» da operação.

Reconhecendo estas dificuldades, na página seguinte, estabelecia-se que a operação de adição de superfícies era possível, mas não uniforme, pois $« \mathrm{~S}_{1} \neq \mathrm{S}_{2} ; \mathrm{S}_{2} \neq$ $\mathrm{S}_{3} ; \mathrm{S}_{1} \neq \mathrm{S}_{3} \gg(\mathrm{p} .58)$. Segue-se depois uma discussão sobre a diferença de duas superfícies e a Figura VII mostra como ela era associada a operações sobre conjuntos. 
FIgURA VII. Ilustrando a diferença de duas superfícies na Lição $n .^{\circ} 4 I$ (Boletim IMAVE, I966, p. 58).

b) $\mathrm{O}$ professor, também a partir de esquemas gráficos, introduz o conceito de diferença de duas superficies (figuras planas) :

S

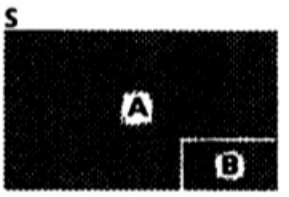

S S = A B B

B)

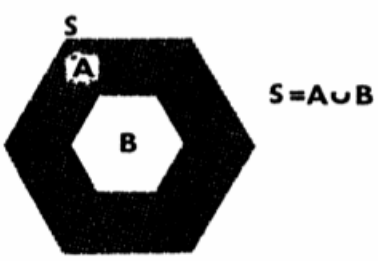

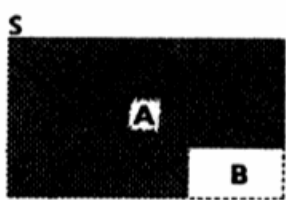

$A=S 、 B$

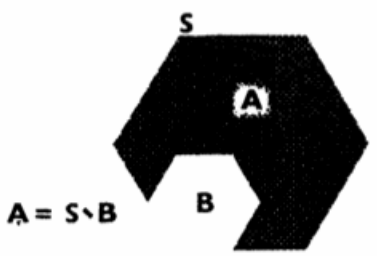

Tal como para a adição, observa-se que a operação diferença de duas superfícies não é uniforme. A adição e a subtracção definida no conjunto das figuras geométricas, levantam muitos problemas matemáticos e deve ter havido dúvidas sobre o interesse da sua introdução no currículo, pois, mais tarde, o tema não é retomado. Para além de não serem uniformes, o resultado das operações pode conduzir a figuras geométricas não convexas, ou mesmo não conexas. Por outro lado, não possuem estrutura de grupo, não tendo, pois, qualquer similitude com as operações aritméticas.

Seguidamente discute-se «a multiplicação de uma superfície (figura plana) por um número natural e a divisão por um número natural» (p. 58) (Figura VIII).

FIgURA VIII. Ilustrando a divisão de uma superfície por um número natural na Lição n. ${ }^{\circ}$ 4I (Boletim IMAVE, 1966, p. 58).
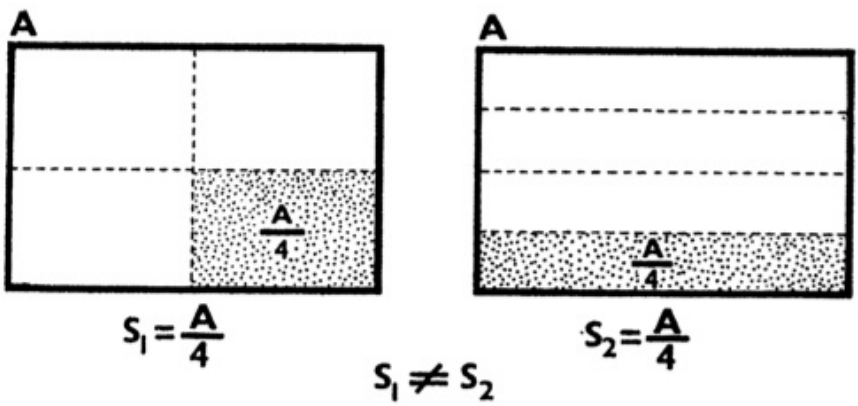
Embora AAL não o comente, a operação volta a não ser uniforme, pois, embora $S_{1}$ e $S_{2}$ tenham a mesma área, não são figuras geometricamente iguais. Dois dias depois, na Lição seguinte, o tema é brevemente retomado através de divisões de rectângulos por números inteiros e estabelece-se o conceito de superfícies equivalentes (as que têm áreas iguais) (Figura IX).

Figura IX. Superfícies equivalentes (Boletim IMAVE, 1966, p. 59).

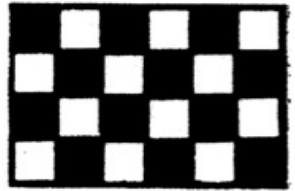

$s_{1}:(6 \times 4) \mathrm{cm}^{2}$

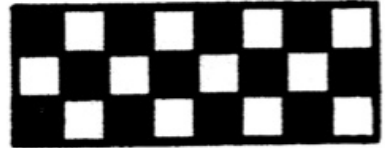

$S_{2}:(8 \times 3) \mathrm{cm}^{2}$

$\mathrm{S}_{1}$ e $\mathrm{S}_{2}$, superfícies diferentes, são equivalentes: têm äreas iguais.

Uma nova imagem torna evidente a afirmação anterior, mostrando que:

1.०) $S_{1}$ contém $6 \times 4$ centímetros-quadrados;

2..$^{\circ} S_{2}$ contém $3 \times 8$ centímetros-quadrados.

b) A area de uma superficie (em princípio, uma figura plana) é concebida como um numero que se faz corresponder $a$ essa superficie (e a todas as que Ihe são equivalentes).

Tomando como unidade de medida das superficies a superficie de um quadrado de lado igual d̀ unidade de comprimento, $e$ atribuindo-lhe a drea 1, então, a medida e a drea de uma superficie exprimem-se por um mesmo nimero.

Assim, dizendo que a unidade $1 \mathrm{~cm}^{2}$ tem a d́rea 1 , se uma figura tem a superficie de $25 \mathrm{~cm}^{2}$, a sua drea é 25 .

O tema das operações sobre figuras planas não é retomado em 1968/69 quando é introduzido um novo programa para alunos desta faixa etária.

Nos exemplos anteriores temos um raro exemplo de elaboração do conhecimento específico do conteúdo. Baseando-se em operações sobre conjuntos, AAL aplica a interpretação que a matemática moderna faz das operações aritméticas (operações sobre conjuntos) a figuras geométricas e, embora os resultados sejam matematicamente muito discutíveis, ilustram como um conteúdo matemático foi gerado por um professor para ser aplicado em contexto escolar.

\section{Saberes do professor e do monitor}

As operações sobre superfícies, com uma forte ênfase na linguagem de conjuntos, abordadas pelo professor essencialmente nas Lições n. ${ }^{\circ} 4 \mathrm{I}$ e 42 , que analisámos na secção anterior, não são retomadas nas actividades de exploração recomendadas para aquelas lições e conduzidas pelo monitor. $\mathrm{O}$ contraste entre as intervenções educativas do professor e do monitor pode ser observado na Figura X, referente à 
Lição n. ${ }^{\circ}$ 4I, onde se apresentam as tarefas a propor pelo segundo aos alunos. Estas tarefas, envolvendo essencialmente a resolução de exercícios sobre a conversão entre unidades de massa, um problema sobre múltiplos formulado em termos de conjuntos e a resolução de expressões numéricas, são muito distantes dos conteúdos abordados pelo professor na mesma lição e que analisámos atrás. Na lição seguinte pretende-se de novo que o monitor proponha mais alguns exercícios

\section{FIgura X. Tarefas a propor pelo monitor na Lição n. ${ }^{\circ} 4 \mathrm{I}$} (Boletim IMAVE, I966, p. 58).

\section{b) No quadro}

1. Calcular:

1.) $7,4 \mathrm{~g}+575 \mathrm{mg}+3,47 \mathrm{dg}$ (em centigramas);

2. $\left.{ }^{\circ}\right) 234 \mathrm{hg}+15,6 \mathrm{dag}+0,8 \mathrm{~kg}$ (em decagramas:.)

2. Determinar :

1.०) O conjunto A dos múltiplos de 8 compreendidos entre 50 e 90 .

2. $\left.{ }^{\circ}\right)$ conjunto $B$ dos múltiplos de 16 compreendidos entre 45 e 100.

3. ${ }^{\circ}$ O conjunto $A \cap B$.

3. Calcular :

$$
\begin{aligned}
& x=(2+4 \times 3): 7+(2 \times 3-1) \times 4: 5 \\
& y=6 \times 4: 8+2 \times(3+1 \times 2)-(2+4 \times 2): 2
\end{aligned}
$$

\section{Respostas :}

1. 1.०) $\left.832,2 \mathrm{cg} ; 2.0^{\circ}\right) 119$ dag.

2. 1.॰) $\left.A=\{56,64,72,80,88\} ; 2 . .^{\circ}\right) B=\{48,64,80,96\}$

3.०) $A \cap B=\{64,80\}$

3. $x=6 ; y=8$.

O Exercício de Apuramento está-se a aproximar (será na Lição n. ${ }^{\circ}$ 43, daí a cinco dias, na segunda-feira seguinte) e é claro o propósito de preparar os alunos, quer durante estas duas Lições, tarefa que recai essencialmente sobre o monitor.

No entanto, parece adequado conjecturar que, presencialmente, a matemática seria associada a práticas ocasionais de manipulação de materiais e essencialmente de resolução de exercícios conduzidas pelo monitor. Uma parte desses exercícios são conhecimento matemático comum pois referem-se a situações que poderiam ocorrer fora do espaço escolar. No espaço televisivo ocupado pelo professor, por outro lado, dominavam as dimensões de representação associadas ao estabelecimento da linguagem da matemática moderna e portanto mais abstrata, constituindo portanto conhecimento matemático específico. 
Não seria justo, no entanto, simplificar esta análise, distinguindo entre um ensino meramente expositivo e abstrato do professor e outro prático e concreto do monitor. Como um de nós argumentou noutro texto (Almeida, 20I8), a visão de AAL sobre os métodos de ensino valorizavam as abordagens concretas e experimentais. Para ele, uma das fontes de aprendizagem resulta do nosso contacto com o mundo material, com objetos e instrumentos e a utilização de materiais manipuláveis facilita a aprendizagem da matemática, dado que os alunos aprendem a pensar e a transformar o pensamento através do contacto com os materiais. Como consequência, as suas aulas ficaram na memória devido ao uso de elementos concretos (Barros, 20I3). Como conta AAL, «[eu] usava coisas concretas e familiares aos alunos, por exemplo, tinha uma coleção de carrinhos de várias marcas e cores para exemplificar conjuntos» (AAL, I9 de novembro de 2006) e «na televisão, as relações entre conjuntos e as relações binárias, tudo isso era abordado usando modelos» (AAL, 29 de março de 20IO).

\section{Concluindo}

Procurámos identificar o conhecimento comum e especializado do conteúdo matemático e, em particular, determinar como eles evoluíram em consequência da introdução da matemática moderna. Verificámos que os novos conteúdos quase eliminaram o conhecimento matemático comum, isto é, aquele que poderia ser utilizado usualmente em contextos não escolares, substituindo-o por conteúdo matemático especializado codificado na linguagem de conjuntos e suas operações. As operações aritméticas, por exemplo, que anteriormente eram ensinadas recorrem a operações de senso comum (juntar, retirar, multiplicar e partilhar) passaram a ser expressas através de operações entre conjuntos recorrendo a novos termos (cardinal, união, complementar, partição, classes de equivalência, etc.) apenas usados em contexto escolar.

Verificámos ainda como à divisão de funções pedagógicas entre o «professor» e o «monitor» correspondia, embora não de uma forma estrita, uma divisão entre conhecimento especializado e conhecimento comum, respetivamente.

Finalmente, podemos observar o fenómeno raro de produção de novo conhecimento especializado e as consequentes imperfeições resultantes da experimentação de novas ideias matemáticas.

\section{Referências}

Almeida, M. C.: «Matemática pela televisão nos anos sessenta: conteúdos e métodos», in CArrillo Gallego, D.; Sánchez Jiménez, E.; Matos, J. M.; Moreno Martínez, P. L. y VAlente, W. R. (eds.): IV Congreso Iberoamericano de Historia de la Educación Matemática, Actas, Murcia, Universidad de Murcia, 20I8, pp. 13-39.

Almeida, M. C. y Matos, J. M.: «Developing a modern mathematics pedagogical content knowledge: the case of Telescola in Portugal in the middle 1960's», in PyTlak, M.; 
Rowland, T. y Swoboda, E. (eds.): Proceedings of the Seventh Congress of the European Society for Research in Mathematics Education, Rzeszów, Poland, University of Rzeszów, 20II, pp. 2956-2957.

Ball, D. L.; Thames, M. H. y Phelps, G.: «Content Knowledge for Teaching: What Makes It Special?», Journal of Teacher Education, 59 (2008), pp. 389-407.

BARbIER, J.-M.: «Introduction», in Barbier, J.-M. (ed.): Savoirs théoriques et savoirs d'action, Paris, PUF, I996, pp. I-17.

Barros, R. A. C.: A Telescola, perspectivas de alunos e monitores, Mestrado Tese de Mestrado, Universidade Nova de Lisboa, Caparica 2013.

Boletim IMAVE (1965).

Borer, V. L.: «Les savoirs: un enjeu crucial de l'institutionnalisation des formations à l'enseignement", in Hofstetter, R. y Schneuwly, B. (eds.): Savoirs en (trans)formation. Au cour des professions de l'enseignement et de la formation, Bruxelas, De Boeck Supérieur, 2009, pp. 4I-58.

Burke, P.: Varieties of cultural history, Ithaca, Cornell University Press, 1997.

CARIA, T.: «A constituição do saber profissional: uma contribuição interdisciplinar sobre a dualidade do uso social do conhecimento", Análise Social, 224, LII (3. ${ }^{\circ}$ ) (2017), pp. 498-532.

Chervel, A.: «L'histoire des disciplines scolaires», Histoire de l'Éducation, 38 (1988), pp. 59II9.

Chevallard, Y.: La transposition didactique. Du savoir savant au savoir enseigné (2. ${ }^{\mathrm{a}} \mathrm{ed}$. ), Grenoble, La Pensée Sauvage, 1985/1991.

Hofstetter, R. y Schneuwly, B.: «Introduction. Savoirs en (trans)formation. Au cœur des professions de l'enseignement et de la formation», in Hofstetter, R. y Schneuwly, B. (eds.): Savoirs en (trans)formation. Au cour des professions de l'enseignement et de la formation, Bruxelas, De Boeck Supérieur, 2009, pp. 7-40.

Hunt, L. (ed.): The New Cultural History, Londres, University of California Press, 1989.

Imave: Boletim do Instituto de Meios Áudio-Visuais de Ensino (1966).

Julia, D.: «La culture scolaire comme objet historique», Paedagogica Historica. International Journal of the History of Education, vol. 31, Issue sup. I (1995), pp. 353-382.

Matos, J. M. «A resolução de problemas e a identidade da educação matemática em Portugal», in Investigación en Educación Matemática XII, 2008, pp. I4I-I58.

Matos, J. M.: «História da Educação Matemática e Educação Matemática», Anais do ENAPHEM (2020, em impressão).

OCDE: Uma revisão para avaliação da Telescola, Paris, OCDE, 1977.

Shulman, L.: «Those who understand: knowledge growth in teaching», Educational Researcher, I5 (2) (1986), pp. 4-I4.

Teodoro, A. N. D.: A construção social das políticas educativas. Estado, educação e mudança social no Portugal contemporâneo, Tese de doutoramento não publicada, Universidade Nova de Lisboa, I999.

VAlEnte, W. R.: «História da Educação Matemática: interrogações metodológicas», REVEMAT - Revista Eletrônica de Educação Matemática, 2 (2) (2007), pp. 28-42.

VAlente, W. y Hofstetter, R. (eds.): Saberes em (trans)formação: um tema central da formação professores, São Paulo, Livraria da Física. 